İrem Duman Çakır*

\title{
Negotiation of resources in everyday activities of a multilingual Berlin street market: a linguistic ethnography approach
}

\author{
https://doi.org/10.1515/multi-2021-0065 \\ Received June 7, 2021; accepted January 9, 2022; published online mu
}

\begin{abstract}
The Maybachufer Market is an urban street market in Berlin-Neukölln that constitutes a highly diverse urban context by bringing together people of different social, cultural, and linguistic backgrounds. Through linguistic ethnography, this paper explores the negotiation of various resources in everyday communicative practices and activities of this urban space. The market setting with its multiethnic and multilingual community constitutes a spatial repertoire with a rich pool of resources. Although German, Turkish, and English are prominent as local and international lingua francas, various other languages and resources are used in the market activities involving different types and modes of interaction. The study shows that the respective communicative practices, which seem random at first glance, in fact follow specific interactional patterns with respect to communicative goals and interactional roles, including different social relations and identity constructions. While exploring everyday activities and the linguistic behaviours at a highly diverse urban market, the study contributes to our understanding of spatial repertoires, metrolingual and convivial practices, and communicative patterns in multilingual and multiethnic interactions in highly diverse urban spaces.
\end{abstract}

Keywords: highly diverse urban settings; linguistic ethnography; metrolingualism; multilingual and multiethnic interactions; urban street market

\section{Introduction}

The ethnolinguistic diversity in metropolises enables intense urban language contact and constitutes highly heterogeneous settings for linguistic innovations (cf. Vanderkerckhove 2010; Wiese 2020). Such heterogeneity engenders new forms

\footnotetext{
*Corresponding author: İrem Duman Çakır, Department of German Studies and Linguistics, Humboldt-Universität zu Berlin, Unter den Linden 6, 10099 Berlin, Germany, E-mail: irem.duman@hu-berlin.de
}

Ә Open Access. () 2022 İrem Duman Çakır, published by De Gruyter. (ㄷ) BY under the Creative Commons Attribution 4.0 International License. 
of interaction through mixed linguistic resources, enabling the emergence of new and context-specific styles and varieties. ${ }^{1}$ Ethnographic studies focusing on this situational and interactional context-dependency conceptualise modern urban linguistic diversity under the term "metrolingualism" (Otsuji and Pennycook 2010; Pennycook and Otsuji 2015). The term derives from Maher's “metroethnicity”, a new form of ethnicity that urban life enables through new common grounds "oriented towards cultural hybridity, cultural/ethnic tolerance and a multicultural lifestyle in friendships, music, the arts, eating and dress" (cf. Maher 2005: 83). Metrolingualism relates language to urban space and underlines the contextdependency of linguistic practices. One of these contexts is urban markets, which Pennycook and Otsuji (2015: 177) characterise as "sites of layered multilingualism in which different language resources are mobilised within a flow of other practices." An example of this is the Maybachufer Market in the multicultural Reuterkiez neighbourhood in Berlin-Neukölln, which constitutes a highly diverse urban context, bringing together people from a large range of social, cultural, and linguistic backgrounds.

In this study, a linguistic ethnography approach has been used to analyse social interactions in this highly diverse urban space. The study focuses on the communicative patterns in everyday practices, and deals with the following research question: how are various resources negotiated in different activities at the Maybachufer Market?

By exploring how different linguistic, cultural, and semiotic resources are chosen, used, and mixed at a multilingual and multiethnic Berlin street market, the study investigates different market activities and interaction types, and the social aspects and communicative functions behind the linguistic practices, which are often seen as random and perceived negatively (as "broken language use”, see Duman and Lin 2021, and a threat to the majority culture and society, cf. Wiese, forthcoming). Thus, the study contributes to our understanding of "metrolingual multitasking", i.e., the interconnection of the space, activities, and resources, and "getting things done" through various resources available in the market's spatial repertoire (cf. Pennycook and Otsuji 2014). Furthermore, the social behaviour and language attitudes of the market community set example for 'convivial' practices to get along in diverse settings, where multiculturalism is perceived habitual (cf. Cook 2022; Gilroy 2004).

In the following section the research area is presented. The third section describes the ethnolinguistic case study of the market, while the fourth section

1 Although the study deals with urban diversity, we should acknowledge that the multilingualism and diversity are peculiar neither to urban areas nor to the Western world (see Baumgärtner 2021; McLaughlin 2009). 
documents the findings of the study. Finally, the last section summarises and discusses the results.

\section{Research area: the Maybachufer Market}

The Maybachufer Market is located in the Reuterkiez neighbourhood of BerlinNeukölln, where $47 \%$ of the population has a so-called "migration background"2 (Statistik Berlin-Brandenburg 2017). The market is one of the oldest and biggest street markets in Berlin. Since the 1970s, the Turkish and/or Turkish-speaking community (i.e., migrants, second- or third-generation Germans, or speakers born in Germany with Turkish as a heritage language) constitutes the majority of sellers and customers at the market as well as the largest population with a migration background in this district today. Therefore, the market is also known as the "Turks’ Market” (Türkenmarkt; cf. İçpınar and Taşdemir 2011; Ohliger 2011).

Nevertheless, today many sellers of diverse backgrounds sell their goods at the market and cater for people of different social, ethnic, and linguistic backgrounds. Besides traditional Turkish and Arabic specialities (e.g., fruits and vegetables, textile products, foods, and desserts), it is possible to find African dishes from Ghana, organic products from Brandenburg, jewellery, decorative items, and various other products from all over the world. Today, the market has become a local shopping place for people from the neighbourhood and all over Berlin as well as an attraction for both local and international tourists. The sale of organic products has especially had a remarkable impact on the customer profile. Nowadays, besides the "Turk's Market", the Maybachufer Market is also called the "BiOriental market", which refers to both the oriental appeal of the market and the offered organic products (referred to as "Bio-" in German).

The interviews conducted with the market sellers and customers throughout the study support how ethnolinguistically diverse the market community is. In the seller interviews, Turkish, German, Arabic, Greek, Bulgarian, Twi, and Serbian are mentioned as first languages. Most of the sellers speak German as second language. In the customer interviews, people mentioned 45 different first languages and 18 different second languages, where German, Turkish, and English had a

2 "Migration background" is used to describe a person who, or at least one of whose parents, was not born as a German citizen. This includes (1) foreigners, (2) naturalised people, (3) (late-)immigrants, (4) people who have obtained German citizenship through adoption by German parents, and (5) the children of the first four categories (Statistisches Bundesamt 2019). The term is mostly used in an exclusionary way and has been discussed critically from a sociolinguistic point of view (cf. Scarvaglieri and Zech 2013). 
prominent place in both categories. Although not all of these languages ${ }^{3}$ are actively spoken at the market, the data support the multiplicity of potential linguistic and cultural resources available in this urban space.

Although cultural and linguistic diversity has existed for a long time in this urban space, the market has only recently become an asset for local pride and has been advertised in almost every Berlin city guide by virtue of its "multi-kulti" (multicultural) nature. This also indicates that this long-existing diversity, which is the norm for the people who belong in this highly diverse urban area, is regarded as a new and interesting phenomenon. This can be related to the national language ideologies and the perception of a monolingual habitus which are presupposed in many European countries following the "one nation, one language” tradition (see Duman and Lin 2021; Gogolin 1994).

The ethnolinguistic diversity at the market creates fruitful settings to investigate the social interactional dynamics among people of different backgrounds, where we observe different kinds of multilingualism, variation, and codeswitching. ${ }^{4}$ The study of such settings provides an understanding of the contextspecific use of spatial repertoires in different communicative practices and the social aspects behind them.

\section{The ethnolinguistic case study of the Maybachufer Market}

\subsection{Methodology}

\subsubsection{Linguistic ethnography as research methodology}

Linguistic ethnography (LE) is an interdisciplinary approach at the interface of culture and language. By combining empirical and theoretical perspectives of linguistics and ethnography, LE focuses on "how social and communicative

3 It is also worth mentioning that the quantification of languages is a very controversial subject. The "languages" mentioned here are named languages that the informants stated, which we essentially acknowledge as social, political, and historical constructs (cf. Makoni and Pennycook 2007).

4 While acknowledging that "code switching" is a controversial term, here it is used as an umbrella term to indicate all kinds of language mixing phenomena regardless of the speech production of individual speakers. In this sense the term can be understood as "alternation among different speech varieties within the same event" (Gumperz 1996: 365) or "alternations of linguistic varieties within the same conversation" (Myers-Scottons 1993: 1). 
processes operate in a range of settings and contexts" (see Rampton et al. 2004; Shaw et al. 2015). A combination of these disciplines is mutually beneficial since linguistics helps delimit the broad empirical scope of ethnography, while ethnographic approaches provide a broader perspective on the analysis of everyday linguistic practices by taking all potentially relevant aspects regarding the social context of interactions into account (cf. Creese 2010: 139).

LE adopts ethnographic data collection and analysis methods, and blends them with the methods of applied linguistics and sociolinguistics to capture everyday linguistic activities. Since LE offers a large methodological perspective on data collection and analysis, it finds many applications in various research fields, such as the study of interaction, identity research, and literacy studies (see Copland and Creese 2015; Lefstein and Snell 2011; Pérez-Milans 2016).

Markets in multilingual and multiethnic urban areas constitute a fruitful research field for ethnolinguistic studies by virtue of their informal setting. In addition to Pennycook and Otsuji's work (2015), a considerable number of studies have researched urban markets (see Creese et al. 2017 on translanguaging at the Bull Ring Market in Birmingham; Busch 2010 on hospitality and hostility at a street market on the German-Polish border; and Hochuli 2019 on seller-customer interactions at a fruit and vegetable stall at a public market in Zurich).

This study contributes to previous research on markets by investigating the multilingual and multiethnic Maybachufer Market in Berlin. Following the LE approach, the study employs both linguistic and ethnographic methods, such as linguistic landscaping, audio/video recordings, transcriptions, sociolinguistic/ ethnographic interviews and focus group discussions, participant observation and field notes, and conversation, micro- and genre analysis, and multimodal approaches for the data analysis. With extensive and multimethod data collection and analysis, the study explores patterns of social interaction and negotiation of various multilingual resources with respect to different market activities.

\subsubsection{Combining different methods}

The linguistic landscape (LL) study provides information regarding the languages ${ }^{5}$ that are present at the market and how they are represented. The LL study offers, as Blommaert (2013: 7) puts it, a "first-line sociolinguistic diagnostic" of the language

5 It is also important to note that what is referred to as "languages" in the LL study consists of linguistic elements that are associated with different named languages. Although the linguistic resources are much more fluid in the local contexts to be labelled in fixed categories, to make an LL analysis, a "language" assessment is made with respect to the social context of the specific stalls (i.e., the sellers, the products, and the target customers). 
use in the particular social settings. However, since LL only provides information regarding the written language use and since not all market stalls have signs, it falls short of giving a complete view of the market's repertoire.

Goffman (1981: 144) argues that in discursive interactions "the whole social situation, the whole surround, must always be considered". Considering a social situation as "the full physical arena in which persons present are in sight and sound of one another", the social (participants) and physical (spatial positioning, orientation to objects, etc.) settings would change how people talk and what they say (cf. Goffman 1981: 136; Rampton 2018: 2). Furthermore, Clark (2003: 244) suggests that acts of communication taking place in a material situation play an essential role in that communication. This means each pointing, placing, and directing is part of the communication and serves as an index to co-construct meaning in situ. Therefore, audio and video recordings, as well as participant observation, were employed to investigate the discursive interactions and communicative patterns. Through random sampling, the spontaneous speech data, hence, vernaculars and the real market language in use, are captured. Through videos and observations, language in situ, nonverbal cues, and multimodal aspects of the communication are explored. The interactive patterns were annotated, partially transcribed, and examined through conversation analysis and micro-analysis methods.

The background information regarding the location, visitors, history, and present state of the Maybachufer Market provides insights into the participants. However, this enables only etic and rather a priori approaches regarding what is to be expected in communicative practices. To obtain emic perspectives, inside information has been gathered through sociolinguistic/ethnographic interviews. Thus, data regarding the participants' social, cultural, and linguistic backgrounds as well as the resources that they have access to have been collected.

Furthermore, participant observation served to better understand social relations, hence sociolinguistic behaviours, between sellers and customers as well as among sellers. It provided the opportunity to experience the social situations as a participant on the seller side of the stall. This also allowed to be included in the respective social category (i.e., sellers as a labour group), rather than being regarded as an outsider. Thus, more insight and reliable data regarding the activities were collected.

Finally, follow-up interviews and focus group discussions were held to check the results and confirm the acceptability and correctness of discovered patterns. Thus, by combining the aforementioned methods, a holistic view of the linguistic resources people use, different channels for the communication (e.g., signs, gestures, speech), and communicative patterns that emerge at the market has been obtained. The respective findings are discussed in Section 4. 


\subsection{Data}

The study is part of a larger project on "Integration of linguistic resources in highly diverse urban settings: Stretching the limits of variability" ${ }^{6}$ The data for this study were collected in the scope of that project. ${ }^{7}$

The data presented in this paper primarily come from

- the LL study conducted between 2017 and 2018, where a total of 426 market signs in the whole market area (55 market stalls and their surroundings) were photographed and analysed,

- interviews conducted with 230 customers (with an age range between 16 and 86) and 31 sellers (incl. pre- and follow-up interviews and focus group discussions),

- transcriptions $^{8}$ of the recordings (ca $82 \mathrm{~h}$ of spontaneous speech data) that were made between October and November 2017 on multiple market days at four cooperating stalls: a fruit and vegetable stall, a Turkish bread and pastry stall, a Turkish coffee stall, and a textile and utensils stall, as well as

- a 3-month participant observation that I conducted by working as a seller at the Turkish bread and pastry stall.

\subsection{The researcher}

The study presented in this paper, like every ethnographic study, reflects to some extent my subjective perspective as a researcher who is well acquainted with street markets and with the dominant cultures and languages of the Maybachufer Market. I was born and raised in Turkey, with Turkish as my native language and with a weekly street market on the street where I lived. I have lived in Germany for almost nine years and speak German as a late-acquired second language, in addition to English and French, which I studied. My personal background became especially

6 Funded by the Deutsche Forschungsgemeinschaft (DFG, German Research Foundation) Project ID 317633480 - SFB 1287, Project A01.

7 The data collection was performed within the ethics framework and related data protection regulations. For the on-site customer interviews oral consents and for detailed seller interviews written consents of the informants were collected. For the audio and video recordings, permission from the market management as well as the written consent of the stallholders were collected. In addition, the market community was informed by signs stating that the respective stalls were being recorded for scientific purposes.

8 For the transcribed data presented in this paper, the GAT2 basic transcription conventions were used (Selting et al. 2009). However, since the research does not include phonological analyses, the relevant features are not considered. 
useful while collecting (and analysing) data from Turkish-speaking informants who were inclined to (and on some occasions did) refuse to give interviews in German due to linguistic insecurities. Furthermore, being a multilingual speaker acquainted with market interactions allowed me to find different common grounds with the market community and easily adapt while working as a seller at the market. I did not stand out as an outside researcher, which could otherwise hinder the observation by causing a possible change in attitude in other participants. The study and analyses thus also include, alongside the discussed theoretical background and scientific approaches, my own observations and interpretations with respect to my personal and academic background as a young sociolinguist.

\section{Findings: market activities, interaction types, and the use of resources}

A market situation constitutes a multi-focused gathering where multiple persons are present and various encounters are carried out (cf. Goffman 1966: 91). In this particular social gathering at Maybachufer, we distinguish four main types of interaction representing different discursive events: (1) the one performed through market signs (i.e., the LL), (2) market crying, (3) sales conversations, and (4) small talk. The social interactions at the Maybachufer Market differ with respect to the activity types they are embedded in and to the generic resources, i.e., prototypical discourse types and genres. Levinson (1979) introduces activity types as "a fuzzy category whose focal members are goal-defined, socially constituted, bounded, events with constraints on participants, setting”. Based on Levinson's definition, the interactions at the market can be categorised under three main types of activity: advertisement, sales, and socialising. Each activity involves different linguistic, semiotic, and generic resources, aims to accomplish different goals, and has different participants with different degrees of participation and/or involvement in the activity.

\subsection{Advertising}

At the Maybachufer Market, the advertising is performed through different generic resources that differ in modes and channels, such as market signs and market crying. The market signs use the visual channel and display textual information regarding the kind, ingredients, origin, and price of the products. Even though they differ in shape, size, and amount of information provided, they serve to promote 
- Vegetarischer Wrap mit

Tomate, Rucola und Kombi*

- vegetarian wrap with

tomato, rucolá and kombi*

2 Lebensmittelzubereitung zum Úberbackeñin

ivir Fülungeh und Salat

\section{Katmer/Gözleme}

Figure 1: Turkish name of the dish with descriptive translations in German and in English.

the product and are composed in a specific style characterised by the use of key words and short information instead of sentences (see Figures 1, 3 and 4).

As an interaction type, the market crying can be considered a platform/stage event (Goffman 1981: 138). The physical arrangement of the market, which separates sellers and customers, creates multiple stages where sellers perform their advertising. The only speaker in this interaction is the seller. The addressees (i.e., the customers) do not reply in a direct way in this focused interaction. With rhymes and melodic phrases, similar to jingles, repeated throughout the market day, market crying represents a specific genre that is particular to market sellers as a social group and performed for a specific goal (i.e., for advertising the products, attracting customers' attention). As a discursive genre, market crying shares similarities with other genres such as TV/radio advertisements and singing (see Lefstein and Snell 2011: 41 for an overview of discursive genres). Such generic resources make it even more similar to stage events. Market (or street) cries are known since medieval times in Europe and were highly popular in the 18th century in urban centres, especially in London street markets (Hindley 1884; Jones 2016). Although this tradition has been kept by only a few vendors in European street markets, today market crying is still a characteristic feature of Turkish bazaars. Also known as a Turkish market, the Maybachufer Market also preserves this tradition. The resources of the market cries differ from stall to stall and generally include praising of products, announcement of discounts, calling to potential customers passing by, funny/catchy phrases, or made-up songs/rhymes about different products to attract attention.

In advertising activities, we predominantly see the use of the dominant market languages: German, Turkish, and English. When we look at the overall language use on market signs, German can be considered the local lingua franca, whereas English is seen as an international language and Turkish is the dominant 


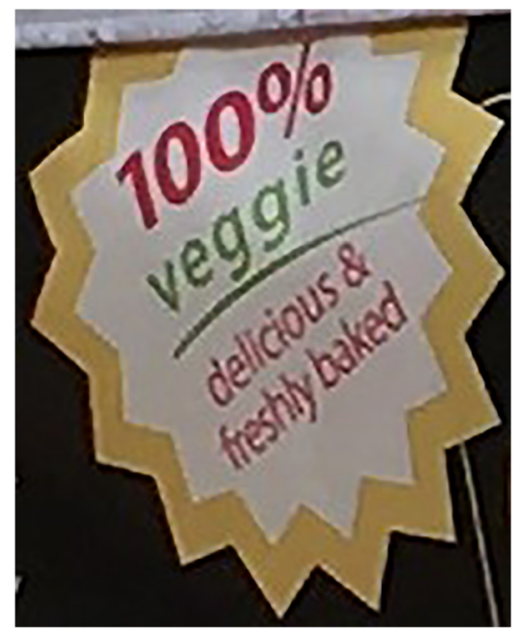

Figure 2: Commodification of English.

heritage language at the market. German has the most semantic functions (e.g., informative, descriptive, directive, symbolic/emblematic) among the languages and is used both in product names and in secondary information, such as product descriptions, ingredients, etc. We observe that English mainly has descriptive (see Figure 1) and emblematic functions. Regarding its emblematic function, we can suggest that English is commodified due to its language prestige and is used in advertising slogans as in Figure 2 (see also Duman and Lin 2021).

To find a possible link between the choice of language used on a sign and the stall type, the stalls and their signs were subdivided into the following categories: foods and drinks, fish and meat, cheese-meze-olive, fruits and vegetables, other edibles (e.g., candies, spices), textile, and others (e.g., decorative items, jewellery, advertisement signs). The findings showed that the use of a language is strongly associated with the micro-ecology of the stall. Haugen (1972: 325) defines the "language ecology" approach as "the study of interactions between any given language and its environment". When we consider the market context as a whole, its settings create an ecology of language in which specific communicative patterns and resources are employed. Correspondingly, the stalls have specific settings which require and/or enable the use of specific resources, depending on the products they offer, which influence the stall set-ups and the specific customers they attract. Thus, the stalls constitute separate micro-ecologies within the market context and allow for different communicative practices. For instance, at the stalls mainly visited by locals (e.g., fruit and vegetable stalls), German and Turkish are 


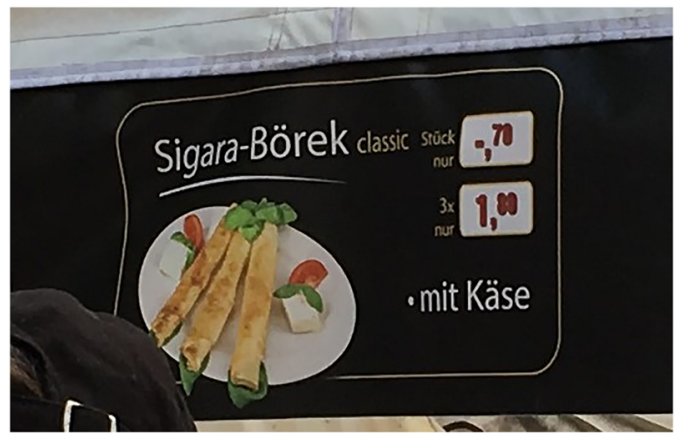

Figure 3: Turkish-German compound.

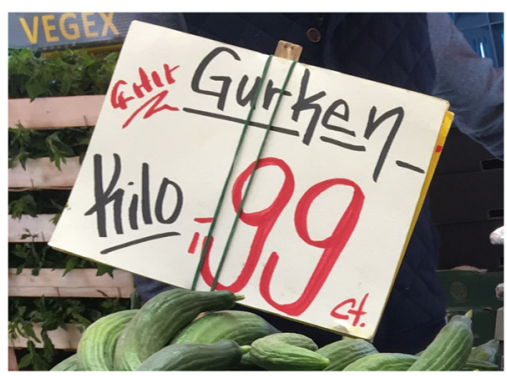

Figure 4: Turkish-German noun phrase.

preferred as the information language. The signs of stalls that primarily attract tourists (e.g., street food or jewellery stalls) are rather written in English. The preference for other languages points to market strategies, through which the speciality of the products is emphasised (e.g., geographical origin as in jamón serrano). In this way, both local and international speakers of these languages are addressed. The signs on which heritage languages are used target the local speakers of the respective languages.

The multilingualism on market signs is not limited to the separate use of different languages. Besides complete or partial translation of texts (as in Figure 1), we observe different elements from different named languages (e.g., product name in Turkish, description or ingredient in German), and creative language mixtures in the form of compounds and/or nominal phrases, which represent grammatical and graphemic integration of different linguistic resources in the respective language and point to language variations (see Figures 3 and 4). Such language 
mixings and variations indicate the mixed-use of linguistic resources that the sellers have access to. ${ }^{9}$

Similar to the market signs, the market cries include mostly German and Turkish, and are again especially heard at the stalls where mainly locals do their shopping. Here again, we observe the mixed-use of different linguistic resources, which is realised through code-switching, primarily between Turkish and German:

(1) "Hallo, lecker lecker lecker bei uns, alles frisch, alles lecker bei uns! Buyrun efendim, buyrun, tazeler, simitler, gevrekler, açmalar, ablalar, bittschön!

((= Hello, yummy yummy yummy at our stall, everything fresh, everything yummy at our stall! Come on, sir, come on, fresh ones, simits, crispy ones, Turkish bagels, Sisters, come on!))

(2) “Angebot Abla, bittschön!”

((= On sale Sister, come on!))

(3) "Frische Brot, taze Brot!"

((= Fresh bread, fresh bread!))

(4) “Gel Abla, gel! Angebot, Angebot, Angebot! Almanya-Ware on Euro!” ((= Come Sister, come! Sale, sale, sale! Germany-products 10 Euro!))

The code-switching during market crying occurs both on the sentence (as in example (1)) and word level (as in example (2)), and similar to market signs, also include mixed nominal phrases (as in "taze Brot" in example (3)) and compounds (as in Almanya-Ware in example (4)). ${ }^{10}$ The switching in example (2) can also be considered a switch into a possible market register. "Angebot" and "bittschön" are among the words/phrases that we often hear in market interactions regardless of the respective language of communication. "Bittschön”, in particular, is predominantly used as an attention-seeking discourse marker with different functions in different communicative situations. It generally includes an invitational function in market cries, whereas in sales conversations, it functions as a welcoming service offer, an attention-seeking marker while handing over a purchased product or money, or as a reply to accept thanks/gratitude from someone. Therefore,

9 See Duman and Lin (2020) for a detailed analysis of the linguistic landscape of the Maybachufer Market compared with the linguistic landscape of the Dong-Xuan Centre in Berlin.

10 See Yüksel (2019) and Yüksel and Duman (2021) for a detailed analysis of the code-switching phenomena at the Maybachufer Market. 
depending on the occasion, it can be translated as 'come on', 'yes, please', 'here you go', or 'you're welcome'.

Although it is not as prominent as German or Turkish, English can also be heard in market crying. Its use is generally limited to shorter phrases such as "It's mango, avocado time!" or it is used as an interjection, wrapped in German market cries, which can be considered another commodification, since it does not transfer any information but is used to attract attention, cf. (5):

\author{
“Angebote, let's go! Aus meine Garten, meine Hühner” \\ ((= On sale, let's go! From my garden, my chickens $))$.
}

\title{
4.2 Sales and socialising
}

The sales encounters represent focused interactions in the form of a talk/conversation (Goffman 1981: 130-1) that includes different sequences, such as greeting, service offer, exchange of information/negotiations about the products and prices, product request, preparation of the product, product offer, purchasing, and farewell. These sequences show differences with respect to the micro-ecologies of different stalls and involve different resources. For instance, the preparation sequence at the bread and pastry stall (i.e., heating up the products, filling the Turkish pizza, boxing or wrapping up products) provides more time for sellers and customers to interact in comparison with other types of stalls where the products require less (if any) preparation. Such conversations include a wide range of genres, and we observe genreshifting through the use of specific resources in different sequences. For instance, a specific accent or a lexical choice can open a new topic and turn the sales encounter into a socialising activity through small talk (see Excerpt 1). Small talk constitutes another interaction type that generally includes asking about each other's well-being and discussing the latest news (e.g., small talk with regular customers), chitchat on a variety of themes such as the weather or current events (e.g., holidays), discussion about the products (i.e., their production process, ingredients, traditional ways of cooking/baking and consuming them), or a game of guessing the country of origin, ethnic belonging, or the first language of the interlocutor.

In contrast to market signs and market crying, which address larger customer groups by using dominant languages, the linguistic resources in sales conversations and small talk involve various languages that are used according to the context and the individual speakers. However, in sales conversations, the range of languages used is closely related to the stall type, as in market signs. The microecologies determine the languages that are spoken at different stalls. For instance, the textile and utensils stall and the fruits and vegetables stall host more local 
customers, and we hear mostly German and heritage languages such as Arabic and Turkish in the sales conversations; whereas the coffee stall, which offers traditional Turkish coffee cooked on hot sand, has a more touristic appeal due to its authentic stall atmosphere. Thus, it is more likely to hear different languages at this stall. The micro-ecology of the Turkish bread and pastry stall involves an even wider range of languages, since the stall appeals to both locals who buy their daily bread and to tourists and other visitors who would like to try Turkish specialities.

In sales and socialising events, we generally observe a tendency and willingness to switch to the language of the interlocutors as a linguistic behaviour. The interviews with the sellers and customers showed that in sales conversations, the communication language is chosen according to:

- assumption of a lingua franca (German or Turkish for locals, and English for tourists)

- semiotic cues such as appearance, clothing, head scarfs (including how they are worn)

- pre-knowledge about the language spoken by the interlocutor (e.g., regular customers)

- simple reaction to the spoken language (including a specific accent)

- overheard conversations in a specific language (e.g., while customers are approaching the stall), and

- spontaneous decisions.

The language switches occur in different sequences of the sales conversations. If the seller has no previous knowledge about the customer, s/he will intuitively decide in which language $s /$ he will start a sales conversation. In our interviews, sellers asserted that with years of experience, they had become experts on recognising customers' ethnic origins and guessing the language they speak. If there are no specific clues, they start the conversation with German as the default.

Excerpt 1 Sales conversation and small talk at the bread and pastry stall (German is given in bold, Spanish in italic)
01 Seller:
HALlo,
$((=$ Hello $))$
02 Customer1: hello! (.) eh: : what are the ingredients of this,
03 Seller: eh, das is (.) eh spinat-cheese, cheese eh: : [patata
PAtata
((= Eh this is spinach-cheese, cheese eh potato, potato))
04 Customer1:
[but I don' $t$ WANT
(. ) I don't want with eh spinaches (-) I don't like. 


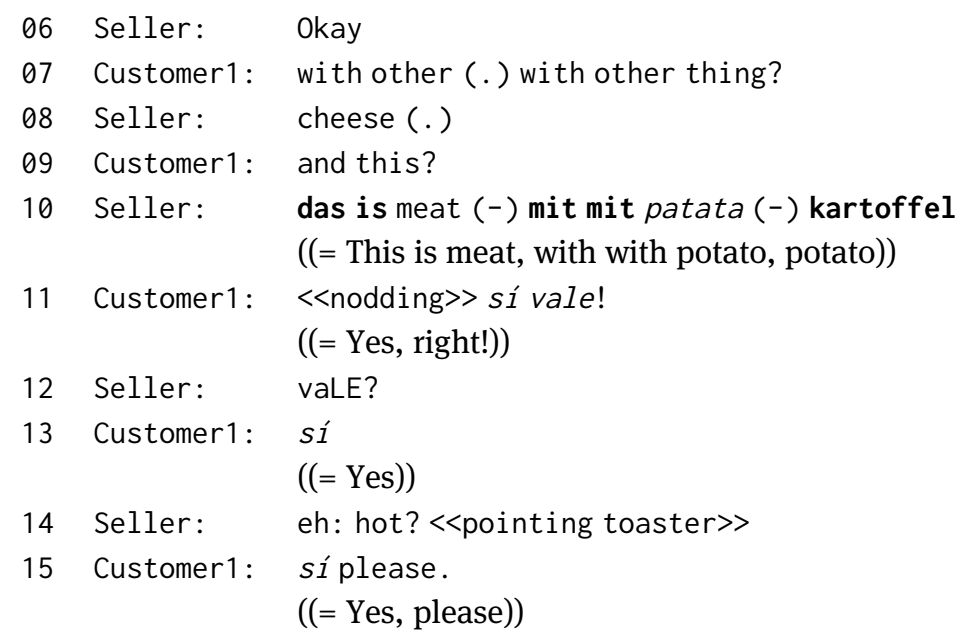

16 Customer2: SÍ?

$((=$ Yes? $))$

17 Customer1: yes yes yes!

18 Customer2: das ist spanisch

((= It is Spanish))

19 Seller: okay okay (.) ich weiß (-) spanisch (.) gracias gracias ((= Okay, okay, I know. Spanish. Thanks, thanks!))

20 Customer1: gracias

((= Thanks))

21 Customer2: danke ((= Thanks))

22 Customer1: danke danke ((= Thanks, thanks))

23 Seller: <<confirming>danke>. $((=$ thanks $))$

((conversation interrupted by another customer))

24 Seller: esPaNola? <<to Customer1>>

((= Spanish?))

25 Customer1: <<nodding>esPANola;> ((= Spanish $))$

26 Seller: MAdrid?

27 Customer1: <<shaking head>NO> cordoba;

28 Seller: <<nodding>corDOBA.> 
In this sales conversation, the seller starts the conversation by saying "Hallo", but the course of the conversation and the linguistic choices change once Customer1 starts to speak. Since the customer does not speak German, she prefers to answer in English, assuming English as the international lingua franca. The seller, then, switches to English. Since he has picked up an accent cue, which he thinks is a Spanish accent, he uses the Spanish word patata (instead of English 'potato'). He thus accesses the linguistic resources he has at his disposal and tries to facilitate the communication. We also see that various other resources are employed to conduct the conversation, hence, the relevant activity. In sales interactions, anything displayed and/or present at the stall can be used as a resource to communicate. Multiple objects are expressed through demonstratives such as this and that and indicated through pointing. Also, the combination of verbal and non-verbal resources in line 14, where the seller asks if he should heat up the product, shows how physical settings play a role in the communication and how pointing and directing serve as indexes to co-construct the meaning in situ.

The excerpt also shows how the sales conversation becomes small talk. The fact that Customer1 uses Spanish words (see line 11) and has a Spanish accent opens a new topic and starts some small talk, in which the seller tries to guess where the customer comes from. Such socialising activities thus fill the gaps in sales encounters, especially in preparation sequences. By using Spanish words, the seller implies that he has some knowledge of Spanish and Spain and uses this knowledge for small talk with the customers (see lines 19, 24, and 26). This can be regarded as a marketing strategy to win the sympathy of customers and a sort of identity construction, which reflects the multicultural nature of the market. In this sense, such small talk can also be considered a "convivial practice”, where people get to know each other, make 'language checks' and use the respective linguistic elements to better address one another, and 'enjoy and engage in casual diversities' (cf. Cook 2021: 17; Pennycook and Otsuji 2015: 89).

The participation framework in sales conversations and small talk may involve both addressed and unaddressed recipients. Large market stalls which position customers side by side and allow sellers to offer service to multiple customers simultaneously also allow side participants and eavesdroppers to get involved in the conversations. Such involvement becomes especially practical when there is a communication problem. We see an example of such side involvement in Excerpt 1, where Customer2 intervenes in lines 16 and 18 and remarks that Customer1 speaks Spanish (instead of English), and again in line 21, where Customer2 teaches Customer1 how to say thanks in German, after she says "gracias". At this point, the sales interaction becomes a language lesson.

Another example of the use of different linguistic and semiotic resources is given in Excerpt 2. 
Excerpt 2 Sales conversation at the textile stall among the seller and two unacquainted customers

Situation: The L1 of Seller2 is Arabic. She can speak German and knows some words and/or phrases in various other languages that she has acquired at the market for sale purposes. Seller2 is talking to Customer3 in Arabic when Customer4 with L1 Turkish approaches the stall.

(Turkish in italic, German in bold)

01 Customer 4: <<to Customer1, points the seller>>bak. (-) anlamıyomben ne 02 (diyor) (...)

((= Look. I don't understand what she says))

03 Customer3: du turkisch (-) äh ich arabi (-) arabic, aber e:gal isch

((= You (are) Turkish, uh I (am) Arab-Arabic, but regardless I-))

$<<$ uses body language and hand gestures indicating she can help her to communicate $>$

04 Seller2: ja (-) muss reden $(-)$ muss reden $a b l a$.

((= Yes, (one) must speak. (One) must speak, sister.))

05 Customer 4: sa(g) mal

((= Tell me then))

06 Seller2: die kundi muss reden ha:?

((= The customer must speak, right?))

07 Customer4: (---) mayo var $m_{1}$ ?? <<showing her body wi th a hand gesture>> $((=$ Are there any bathing suits?))

08 Seller2: mayo ( ) (1.52) mayo yok abla (-) winter äh abla (-) $((=$ Bathing suit? There are no bathing suits, sister. Winter uh sister))

09

keine mayo in winter $(-)(.$.

((no bathing suits in winter))

10 Customer 4: doch (. ) hause((presumed meaning: a bathing house))

((= but yes, house/home) $)$

11 Seller2: zu [hauSE: : ?

$((=$ at home? $))$

12 Customer 4: [da da hause $(-)$ für baden $<<($ points out a direction $)>>$ ((= there, there, house for bathing))

13 Seller2: Ahh: :

14 Customer 4: ja:

((= yes))

15 Seller2: HAmmam (.) türkisch HAmmam

((= hammam, Turkish hammam) $)$ 
In the excerpt, we again see the combination of a sales conversation and small talk. Customer4 hears the seller speaking Arabic and turns to Customer3 in the hope that she will mediate between the seller and herself. At this point, a conversation starts between the customers. Customer3 recognises that Customer4 speaks Turkish and offers help to mediate between them although she does not speak Turkish. To do that, Customer3 uses simplistic German with syntactical reductions (see line 3). In line 4, Seller2 also gets involved in the conversation and expresses in German that she needs to talk to communicate even if they do not share the same language. Customer4 turns to the seller and first speaks in German but then asks for bathing suits in Turkish. We can speculate that Customer4 cannot speak German well enough to explain what she needs; therefore, she talks in Turkish and supports what she is saying by using an additional channel (i.e., hand gesture). Also, she may have expected that Seller2 would understand Turkish since Turkish is seen as a lingua franca for the spatial repertoire of the Maybachufer Market, which lies in the "Turkish district" ("türkisches Revier") according to the statements of some interviewed customers. The seller with L1 Arabic answers in Turkish. The rest of the conversation is carried out in a mixed language, using different resources from Turkish and German. The miscommunication occurring in lines 10 and 11 is resolved again by using different modes: speech and showing a specific direction (presumably the direction where the hammam lies). This interaction shows that the speakers access all the resources they have at their disposal to conduct a successful communication, including multimodality and resources from different languages. The excerpt also constitutes excellent meta data on language use and how people of different linguistic backgrounds negotiate meaning through various resources to facilitate communication.

In the seller-customer interactions, the choices of resources are premeditated according to their threefold function: communicative, commercial, and with respect to identity constructions ${ }^{11}$ (see Schulte and Duman 2019; Yüksel and Duman 2021). The first goal in any conversation is to communicate. Since the market is a commercial institution, the context of such conversations includes sales purposes and commercial expectations. To conduct a successful communication, and also a successful sale, the speakers refer to resources that take part in the co-construction of identity. Sellers and customers navigate their linguistic

11 The term "identity" has different definitions in the literature. Following Bucholtz and Hall (2005), the term is used here for the interactive process, where speakers position themselves and others. Social identity and belonging are fairly large topics that require special attention, and for reasons of space, they are only briefly touched upon in this paper. A detailed analysis regarding the identification process and related identity markers and linguistic choices at the market will be discussed in a later paper. 
choices according to the presumed ethnic/social belonging of their interlocutor. Evidence for this is seen in the use of specific forms of address in different languages (e.g., the use of abla, 'elder sister' in Turkish, in Excerpt 2). Semiotic resources such as appearance and linguistic features such as accent and lexical choices play an important role in the identification process. By acknowledging these particularities and their social meaning and taking a stance in relation to the constructed identity of the interlocutor, speakers reflect various language attitudes, solidarity, togetherness, or distinction within such a diverse urban context. By using the language of the interlocutors, commenting on their language, country of origin, or ethnic belonging, speakers not only ease the communication but also construct a multicultural and/or metroethnic identity. They present their world knowledge and acquaintance with the respective culture. People like to be spoken to in their first language and to hear nice comments on their culture or country of origin. Through the affective orientation the speakers display in discourse, they show sympathy towards the interlocutors and simultaneously try to find common ground and to gain their sympathy. Sellers use this as a marketing strategy ${ }^{12}$ to sell more products, but also to reflect the multicultural nature of the market. We observe a similar attitude with customers. Customers often try to use the words they know in the sellers' first/heritage languages. For instance, if they are at the Turkish bread and pastry stall, they greet and/or thank the sellers in Turkish regardless of the main communication language during the sales conversation. They also try to learn the Turkish names of the products and some other Turkish words. Thus, we witness how the market turns into a space for learning and cultural exchange. The interest and appreciation of customers towards their language, culture, and the traditional products they sell are very welcomed by the sellers and often rewarded by a small gift or reduction in price.

In the case of interactions between/among sellers, we also see the tendency to speak the language of the interlocutors. The use of Turkish especially stands out in seller-seller conversations. However, the use and choice of resources differ in motivation. In contrast to the commercial use of languages in sales conversations and small talk between sellers and costumers, a group identity comes to the forefront when sellers speak to each other. Since they work side-by-side under challenging outdoor conditions (also at other street markets on different days) and depend on each other for their different needs (e.g., electricity connection), the seller community constitutes a "mobile neighbourhood" and a social group (market sellers as a

12 One could speculate that since the market is a competitive environment, the sellers often try their best to accommodate their customers, who would otherwise do their shopping at the next stall. 
labour group) which shows solidarity among its members, leading to convivial practices. The motivation to learn and use each other's languages is thus related to this neighbourhood feeling and solidarity, including multiethnic solidarity. Excerpt 3 shows a greeting section from a conversation between two sellers.

Excerpt 3 Small talk between sellers

(Seller3 with L1 Turkish, Seller4 with L2 Arabic; Arabic in bold)

01Seller3: wie geht's dir habibi?

$((=$ how are you my dear $))$

02Seller4: wie geht's mein Lieber?

$((=$ how are you my dear $))$

This is a conversation between two sellers with different first languages, where they ask about each other's well-being. Although they both speak German, Seller3 addresses Seller4 with an Arabic form of address habibi ('my dear'). The use of Arabic in this conversation neither facilitates the communication nor includes a sales purpose. Since Seller4 is an Arabic speaker, Seller3 uses Arabic, and with this specific form of address, he indexes how he socially positions Seller4 (i.e., both an Arabic speaker and a dear fellow seller).

Similarly, in Excerpt 4, we see a conversation between two sellers in which the language choices differ in motivation.

Excerpt 4 A conversation between two sellers

(Seller5: L1 Turkish and Seller6 with L1 Serbian; Turkish in italic, German in bold)

01 Seller5: sabunCU

((= Soap-seller $))$

02 Seller6: oh (.) kolay gelsin Seller5

$((=\mathrm{Oh}, \approx$ may it be easy for you Seller 5$))$

03 Seller5: teşekkürler Sabuncu (.) nasılsın?

((= Thanks Soap-seller. How are you?))

04 Seller6: iyim(.) iyim

((= I'm fine, I'm fine))

05 Seller5: iyi ol (.) iyi ol (-) ama çok sıcak giyindin sen bugün

((= Be fine, be fine. But you got dressed too warm today))

06 Seller6: (---) sic-(.) sicak yok

$((=$ Warm-no warm $))$

07 Seller5: sicak yok

((= No warm?))

08 Seller6: sicak [yok

((= No warm $))$ 
09

Seller5:

$((=$ There isn't?))

10 Seller6: langsam (-) im herbst hatte ich eine kleine jacKE (-) zum 11

12

Seller5: für (-) kunde?((laughing))

$((=$ For customer?))

13 Seller6: aber sicak (-) noch nicht (-) später (.) kommt noch

((laughing))

((= But warm, not yet. Later, it will come))

14 Seller5: hast du recht (. ) Sabuncu (-) çay içicen mi Sabuncu?

$((=$ You're right, Soap-seller. Are you going to have a tea Soapseller?))

15 Seller6: nein (.) ich hab zwei

$((=$ No. I had two $))$

After Seller5 addresses the fellow seller as "Sabuncu” (Tur. 'soap seller'), the conversation starts in Turkish, although both speakers speak German fluently. We observe that Seller6 also uses cultural resources, such as the Turkish idiom "kolay gelsin" ( $\approx$ 'may it be easy for you'), which is generally used when someone is working, and is therefore often heard at the market. In line 10, Seller6 switches to German, presumably to better express himself. Although the conversation could be held fully in German, Seller6 prefers to speak in Turkish since his interlocutor is a Turkish speaker. We can speculate that since Turkish is the dominant heritage language at the market, sellers tend to learn some Turkish words to communicate with customers. But the choice of Turkish as code when speaking to fellow sellers could be explained with the neighbourhood feeling and solidarity. From a language attitude perspective, we can compare the use of Turkish (or Turkish words) by non-native/non-heritage speakers of Turkish to the language use of multiethnic urban communities, whose speakers are later generations of "migrants" who grew up in multiethnic neighbourhoods and adopt respective urban vernaculars (cf. Wiese, forthcoming). Being the heritage language of the largest minority community at the market makes Turkish a local lingua franca for the spatial repertoire of the market that is accepted by other members of this multiethnic community. Such 'language sharing' is also an example of convivial practices in multiethnically diverse spaces (cf. Cook 2021). 


\section{Conclusion}

This paper has discussed the findings of a linguistic ethnography conducted at a highly diverse urban street market in Berlin. A characteristic of such diverse urban spaces is that they bring together people of different social, ethnic, and linguistic backgrounds and allow different types of activities and communication using the rich resources that people have at their disposal.

The ethnolinguistic analysis focusing on the Maybachufer Market allowed for insights into the market activities, the internal relations within the market community, different types and forms of interaction, language attitudes, and linguistic practices shaped by the market context and its diverse settings. Such social and physical settings constitute a spatial repertoire specific to the market and create micro-ecologies at different market stalls. Furthermore, they allow for different social dynamics, hence different social interactions within the market community, through a range of linguistic and cultural resources that are used and mixed to communicate and navigate identities. Through the creative and multifunctional use of its spatial repertoire, the market constitutes a social space which is constructed and reconstructed as a commercial institution and as a multiethnic gathering place that allows cultural and linguistic exchange.

The use of German, English, and Turkish is prominent at the market as local and international lingua francas. However, each of these languages together with other linguistic and semiotic resources accomplishes different interactional goals with respect to the activities it is embedded in. German is seen as the dominant language at the market and is primarily used as the default while addressing larger customer groups since most of the market community is considered German speakers. English, on the other hand, functions as an international communication language in sales conversations from the points of view of both sellers and customers. The miscommunications or false guesses regarding the presumed belonging and language of the interlocutors are often repaired by switching into English. Yet, in other activity and interaction types, such as advertising through market crying, we see that English is mostly commodified by virtue of its language prestige. Turkish functions as the dominant heritage language at the market due to the high number of Turkish speakers in the market community. Therefore, we hear Turkish in all activity and interaction types. However, the use of Turkish is not limited to its heritage speakers. It is an example of the metrolingual practices at the market since we observe that the Turkish language is embraced as another local lingua franca by the multiethnic community of the market and used for different purposes in seller-customer and seller-seller interactions. The underlying motivations can be explained as conviviality in this mobile neighbourhood, solidarity 
among sellers and within the multiethnic market community, and related identity constructions as well as the communicative function and commercial use of languages.

The use of various other languages and resources is predominantly seen in sales conversations and small talk and is oriented towards individual interlocutors. The semiotic cues, such as clothing, manners, etc., and linguistic markers, such as language accent and lexical choices, lead to consecutive identity constructions that play an important role in the choice of resources to be employed. Here again, the threefold function of language use (i.e., communicative, commercial, and with respect to identification) come to the forefront.

Through a multimethod ethnolinguistic study, the paper has documented what kind of activities and interaction types we see at the diverse Maybachufer Market, how resources emerge, are used and negotiated in different market activities, and the relevant interactions. The linguistic practices at the market show that the choices of linguistic resources in market interactions neither result from bad/broken language use, nor are random. They follow specific patterns that involve different motivations and expectations in relation to the conducted activities, interactional goals, and participant roles. The ways linguistic and other kinds of resources, everyday tasks, practices and activities, and social space are intertwined at the Maybachufer Market are an example of metrolingual multitasking; in other words, they show how different resources are deployed to achieve different goals. In this sense, the study contributes to our understanding of spatial repertoires, metrolingual practices, and communicative patterns in multilingual and multiethnic interactions in highly diverse urban spaces.

However, the data and analyses discussed in this paper only partially reflect the diverse market context. Furthermore, the observations and interpretations are influenced to some extent by my subjectivity as a researcher; another researcher might observe and find other interesting aspects of the market interactions. The Maybachufer Market has more to offer for linguistic and ethnographic research, and there are more points to be considered with respect to social interaction and linguistic practices in highly diverse environments than one could address in a single paper.

\section{References}

Baumgärtner, Edgar. 2021. Auf der Suche nach dem verloren gegangenen Wort für Frosch: Authentizität russlanddeutscher Dialekte zwischen versuchter Einsprachigkeit und verunsicherter Mehrsprachigkeit. Zeitschrift für Dialektologie und Linguistik 88(1-2). 161-190. 
Blommaert, Jan. 2013. Ethnography, superdiversity and linguistic landscapes: Chronicles of complexity. In Critical language and literacy studies, vol. 18. Bristol: Multilingual Matters.

Bucholtz, Mary \& Kira Hall. 2005. Identity and interaction: A sociocultural linguistic approach. Discourse Studies 7. 585-614.

Busch, Dominic. 2010. Shopping in hospitality: Situational constructions of customer-vendor relationships among shopping tourists at a bazaar on the German-Polish border. Language and Intercultural Communication 10(1). 72-89.

Clark, Herbert H. 2003. Pointing and placing. In Sotaro Kita (ed.), Pointing. Where language, culture, and cognition meet, 243-268. Hillsdale, NJ: Erlbaum.

Cook, William Robert Amilan. 2022. Convivial linguistic practices: Lived togetherness through language in the United Arab Emirates. Multilingua 41(1). 1-28.

Copland, Fiona \& Angela Creese. 2015. Linguistic ethnography. London: SAGE Publications.

Creese, Angela. 2010. Linguistic ethnography. In Lia Litosseliti (ed.), Research methods in linguistics, 138-154. London: Continuum.

Creese, Angela, Adrian Blackledge \& Rachel Hu. 2017. Translanguaging and translation: The construction of social difference across city spaces. International Journal of Bilingual Education and Bilingualism 21(7). 841-852.

Duman, İrem \& Dai-Ying Lin. 2021. Linguistic Landscape im hochdiversen urbanen Raum: Das linguistische Bild zweier Berliner Märkte. In Evelyn Ziegler \& Heiko Marten (eds.), Linguistic Landscapes im deutschsprachigen Kontext: Forschungsperspektiven, Methoden und Anwendungsmöglichkeiten im Unterricht und Sprachmarketing, 165-197. Frankfurt a.M: Peter Lang Verlag.

Gilroy, Paul. 2004. After empire: Melancholia or convivial culture? London: Routledge.

Goffman, Erving. 1966. Behavior in public places: Notes on the social organization of gatherings. New York: Free Press.

Goffman, Erving. 1981. Forms of talk. Philadelphia: University of Pennsylvania Press.

Gogolin, Ingrid. 1994. Der monolinguale Habitus der multilingualen Schule. Münster/New York: Waxmann.

Gumperz, John J. 1996. Introduction to Part IV2. In John J. Gumperz \& Stephen Levinson (eds.), Rethinking linguistic relativity, 359-373. Cambridge: Cambridge University Press.

Haugen, Einar. 1972. The ecology of language. Standford, CA: Standford University Press.

Hindley, Charles. 1884. A history of the cries of London: Ancient and modern, 2nd edn. London: C. Hindley.

Hochuli, Kenan. 2019. Turning the passer-by into a customer: Multi-party encounters at a market stall. Research on Language and Social Interaction 52(4). 427-447.

İçpınar, Canset \& Ebru Taşdemir. 2011. Markt der Sehnsüchte, TAZ (30 November 2011, Berlin; tazSerie Orte der migration, Teil 4). https://taz.de/taz-Serie-Orte-der-Migration/!5106461/ (accessed 20 January 2022).

Jones, Peter T. A. 2016. Redressing reform narratives: Victorian London's street markets and the informal supply lines of urban modernity. The London Journal 41(1). 60-81.

Lefstein, Adam \& Julia Snell. 2011. Promises and problems of teaching with popular culture: A linguistic ethnographic analysis of discourse genre mixing in a literacy lesson. Reading Research Quarterly 46(1). 40-69.

Levinson, Stephen C. 1979. Activity types and language. Linguistics 17(5-6). 365-400.

Maher, John C. 2005. Metroethnicity, language, and the principle of cool. International Journal of the Sociology of Language 175/176. 83-102. 
Makoni, Sinfree \& Alastair Pennycook (eds.). 2007. Disinventing and reconstituting languages. Clevedon, UK: Multilingual Matters.

McLaughlin, Fiona. 2009. Introduction to the languages of urban Africa. In Fiona McLaughlin (ed.), The languages of urban Africa, 1-18. London: Continuum.

Myers-Scotton, Carol. 1993. Social motivations for codeswitching: Evidence from Africa. Oxford: Clarendon Press.

Ohliger, Rainer. 2011. Sinn und Deutung - Erste Schritte auf der Berliner Route der Migration. In Ulrich Raiser/der Beauftragte des Senats für Integration und Migration (eds.), Stadt ist Migration: die Berliner Route der Migration - Grundlagen, 10-26. Skizzen: Kommentare.

Otsuji, Emi \& Alastair Pennycook. 2010. Metrolingualism: Fixity, fluidity and language in flux. International Journal of Multilingualism 7(3). 240-254.

Pennycook, Alastair \& Emi Otsuji. 2014. Metrolingual multitasking and spatial repertoires: 'Pizza mo two minutes coming'. Journal of SocioLinguistics 18(2). 161-184.

Pennycook, Alastair \& Emi Otsuji. 2015. Metrolingualism: Language in the city. New York: Routledge.

Pérez-Milans, Miguel. 2016. Language and identity in linguistic ethnography. In Siân Preece (ed.), The Routledge handbook of language and identity, 83-97. London, UK: Routledge.

Rampton, Ben. 2018. Goffman: Key concepts in exploration of the interaction order. Working Papers in Urban Language and Literacies 239. https://www.academia.edu/36327336/ WP239_Rampton_2018_Goffman_Key_concepts_in_exploration_of_the_interaction_order.

Rampton, Ben, Tusting Karin, Janet Maybin \& Richard Barwell. 2004. UK linguistic ethnography: A discussion paper. http://www.lingethnog.org.uk (accessed 28 October 2020).

Scarvaglieri, Claudio \& Claudia Zech. 2013. Ganz normale Jugendliche, allerdings meist mit Migrationshintergrund. Eine funktional-semantische Analyse von Migrationshintergrund. Zeitschrift für angewandte Linguistik 58(1). 201-227.

Schulte, Britta \& İrem Duman. 2019. Social meaning in sales interactions at a multilingual urban street market. Paper presented at the at the international conference "Meaning in Flux 2019: Connecting development,variation, and change”, 10-12 October. New Haven: Yale University.

Selting, Margret, Peter Auer, Dagmar Barth-Weingarten, Jörg Bergmann, Pia Bergmann, Karin Birkner, Elizabeth Couper-Kuhlen, Arnulf Deppermann, Peter Gilles, Susanne Günthner, Martin Hartung, Friederike Kern, Christine Mertzlufft, Christian Meyer, Miriam Morek, Oberzaucher Frank, Jörg Peters, Uta Quasthoff, Wilfried Schütte, Anja Stukenbrock \& Susanne Uhmann. 2009. Gesprächsanalytisches Transkriptionssystem 2 (GAT 2). Gesprächsforschung - Online-Zeitschrift zur verbalen Interaktion 10. 353-402.

Shaw, Sara, Fiona Copland \& Julia Snell. 2015. An introduction to linguistic ethnography: Interdisciplinary explorations. In Julia Snell, Sara Shaw \& Fiona Copland (eds.), Linguistic ethnography. Palgrave advances in language and linguistics. London: Palgrave Macmillan.

Statistik Berlin-Brandenburg. 2017. Einwohnerinnen und Einwohner im Land Berlin am 30. Juni 2017. Bezirke und Lebensweltlich orientierte Räume (LOR-Planungsräume) von Berlin. http://www.statistik-berlin-brandenburg.de/Statistiken/statistik_SB.asp? Ptyp=700\&Sageb=12041\&creg=BBB (accessed 23 October 2020).

Statistisches Bundesamt (Destatis). 2019. Bevölkerung mit Migrationshintergrund (Ergebnisse des Mikrozensus 2018) in Bevölkerung und Erwerbstätigkeit. https://www.destatis.de/DE/ Themen/Gesellschaft-Umwelt/Bevoelkerung/Migration-Integration/Publikationen/ Downloads-Migration/migrationshintergrund-2010220187004.pdf?__blob=publicationFile (accessed 10 August 2020). 
Vanderkerckhove, Reinhild. 2010. Urban and rural language. In Peter Auer \& Jürgen E. Schmidt (eds.), Language and space: Theories and methods, 315-332. Berlin, New York: de Gruyter.

Wiese, Heike. 2020. Contact in the city. In Raymond Hickey (ed.), The handbook of language contact, 2nd edn. 261-279. Hoboken: Wiley-Blackwell.

Wiese, Heike. Forthcoming. Urban contact dialects. In Salikoko Mufwene \& Anna María Escobar (eds.), The Cambridge handbook of language contact. Cambridge: Cambridge University Press.

Yüksel, Serkan. 2019. Commercial codeswitching por favor - the use of codeswitching to persuade customers. Paper presented at languaging diversity 2019: "Discourse and Persuasion 3.0: Identities in a hybrid and multimodal world", 24-27 September 2019, 24-27. Teruel, Spain: University of Zaragoza.

Yüksel, Serkan \& İrem Duman. 2021. Code-Switching auf einem hochdiversen urbanen Wochenmarkt: Kommerz, Kommunikation und Identität. Linguistik Online 110(5). 157-192. 